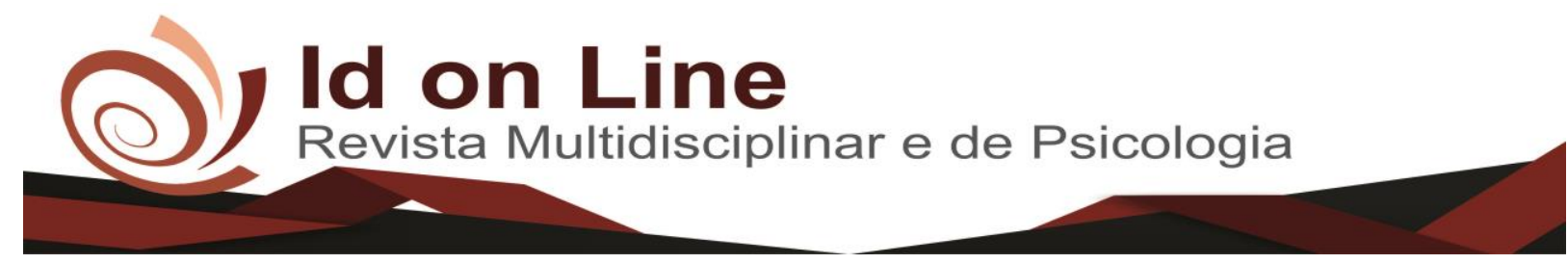

Editorial

\title{
A Ciência explica a Felicidade?
}

Gislene Farias de Oliveira

Resumo: A felicidade caracteriza-se por uma disposição emocional positiva, acompanhada de sentimentos de prazer e bem-estar, em geral associados à uma coerente compreensão do mundo ou do contexto de uma determinada situação. É um fenômeno eminentemente subjetivo, vinculado a traços de personalidade e a dimensões socioculturais. Favorecer situações que levem os indivíduos a reconhecerem as emoções em si e nos outros, bem como uma promoção de políticas públicas de promoção à saúde mental e emocional, podem ser benéficas como ações de prevenção nas áreas social e ocupacional.

Palavras-chave: Felicidade, saúde mental, bem-estar subjetivo.

\section{Does Science Explain Happiness?}

\begin{abstract}
Happiness is characterized by a positive emotional disposition, accompanied by feelings of pleasure and well-being, usually associated with a coherent understanding of the world or the context of a given situation. It is an eminently subjective phenomenon, linked to personality traits and sociocultural dimensions. Favoring situations that lead individuals to recognize emotions in themselves and in others, as well as promoting public policies to promote mental and emotional health, can be beneficial as prevention actions in social and occupational areas.
\end{abstract}

Key words: Happiness, mental health, subjective well-being.

\section{Introdução}

Será que há meios para se mensurar a felicidade? A felicidade é ter uma vida mais tranquila uma vida mais desafiante? Como explicar o estado de felicidade de alguns, enquanto outros em condições semelhantes e, por vezes até melhor, sentem-se desconfortáveis, queixamse em demasia e não parecem ter satisfação com a vida que levam?

Parece haver uma ideia em algumas pessoas de que, a vida do outro parece dar mais certo, ter mais oportunidades do que a delas. Trata-se de uma "constatação" que pode levar a

\footnotetext{
${ }^{1}$ Doutorado em Psicologia social pela Universidade Federal da Paraíba. Pós doutorado em Ciências da saúde pela Faculdade de Medicina do ABC, São Paulo. Professora da Faculdade de Medicina da Universidade Federal do Cariri - UFCA. Contato: Gislene.farias@ufca.edu.br.
} 
uma grande insatisfação com a vida que levam, não prestando atenção ao que há de bom em suas vidas e, que poderia ser melhor aproveitado.

Um jeito de pensar vai contaminando outro, da seguinte maneira: "algumas profissões são mais felizes que outras", "ser religioso trás mais felicidade do que ser ateu" ou, "ser mais bem remunerado ajuda a ser mais feliz", e coisas assim. Pensando desta maneira, toda pessoa numa certa faixa salarial seria feliz. Todos os bailarinos, psicólogos ou floristas seriam os mais felizes.

Há na população, num determinado momento, uma certa preocupação com a felicidade. Quando é que finalmente eu serei feliz? quando me formar?, quando meu salário atingir certo valor?, quando eu casar?, quando os filhos crescerem?. Temos uma tendência a nos referenciar nas outras pessoas, que nos parecem bem sucedidas e felizes.

Médicos, psicólogos e profissionais de saúde que trabalham em ambiente hospitalar, ouvem queixas do tipo: "eu deveria ter feito um pouco mais por mim", "não me sinto preparado para essa adversidade", “o que eu posso fazer para ser feliz?", e coisas do tipo. Na verdade se queixam sobre a vida que levaram e/ou ainda levam, sejam ricos, pobres, jovens, idosos, homens ou mulheres.

\section{A Psicologia Positiva}

A psicologia positiva evidenciou trabalhos de autores como Ed Diener (1984), Csikszentmihalyi (1990), Kahneman et al. (2003), Peterson e Seligman (2004), dentre outros, que trabalham temas como: afetos positivos, satisfação com a vida, felicidade, otimismo, resiliência, qualidade de vida e, gratidão, dentre outros similares.

A busca pelo estado de felicidade parece ter influenciado de forma crescente as novas pesquisas, em muitas áreas afins. Há uma espécie de moda sobre a felicidade, que parece estimulada, em parte pela própria mídia, em parte pelas pesquisas que revelam que a felicidade traz inúmeros benefícios à saúde, além de uma paz emocional e benefícios imunológicos e estímulo à criatividade.

Autores como Cloninger (2004), explicam que a psiquiatria conhece muito bem sobre as características biomédicas de pessoas que se dizem infelizes, mas muito pouco sobre as 
pessoas que sentem-se felizes. Num artigo recente, o autor explica as razões por que a psiquiatria, ainda se concentra em diminuir o mal-estar das pessoas, em vez de buscar aumentar sua satisfação com a vida e seu bem-estar subjetivo.

Num primeiro momento, a psiquiatria parece ter se concentrado nas doenças mentais e não, necessariamente, na compreensão de como aconteceu o desenvolvimento da saúde mental. Num segundo momento, a forma de categorizar e classificar as doenças mentais ainda é muito limitada. Tal ênfase em uma distinção categorial, entre pessoas doentes e pessoas saudáveis, parece aumentar a separação e o contraste entre as mesmas. Noutro sentido, ao colocar-se em foco as intervenções que eliciem a saúde mental de todos, seria um tanto complexo, dado o estigma reinante, ante a doença mental. E mesmo reconhece-la, é difícil, dados os métodos psiquiátricos para diagnóstico e tratamento, que requerem estudos e treinamentos prolongados para tais profissionais, além de, em geral, sair muito caro para os prováveis pacientes. Essa situação, tende a limitar a disponibilidade de muitas intervenções, mesmo que, a um pequeno número de indivíduos (CLONINGER, 2006).

Nesta mesma direção, estudos de Seligman e Csikszentmihalyi (2000), demonstraram que a psicologia, não é somente o estudo das patologias e das fraquezas humanas, mas também concentra-se nas capacidades, na força pessoal e nas virtudes, dimensões importantes para resistir às pressões sociais e laborais. Educar uma criança, neste sentido, não seria, tentar "eliminar" os comportamentos considerados "errados", mas sim, ajuda-la a identificar suas capacidades, seus talentos naturais e, alimentar suas qualidades, seus pontos fortes, para que consigam firmar-se mais competentes emocionalmente e, mais resilientes.

São inúmeras as definições de felicidade, embora normalmente façam menção a um estado positivo emocional, acompanhado de sentimentos de prazer e bem-estar.

Uma definição mais popular de felicidade, é encontrada em dicionários: " Estado da pessoa feliz, satisfeita, alegre, contente (...) satisfação; sensação real de satisfação plena; estado de contentamento ". (DICIONÁRIO on line DE PORTUGÛES, 2018)

Ekman (1992) por sua vez, acredita que emoções básicas implicam em expressões faciais específicas, independentemente da cultura do indivíduo. Também estariam associadas a determinadas alterações fisiológicas e comportamento associado, os quais também teriam um paralelo demonstrável em primatas. Observando-se tais critérios, é possível afirmar-se que a felicidade parece ser uma emoção básica. 
Alguns estados emocionais e experiências vivenciadas parecem produzir felicidade, a exemplo de amor, saúde, alegria, sensação de saciedade, a segurança, o prazer sexual, dentre outros. As emoções tais como o medo, a tristeza, a raiva e o sentimento de asco ou nojo, além de ansiedade, dor, e angústia, tenderiam a diminuir a felicidade.

Cloninger (2004) orienta que "felicidade" é uma expressão que nos leva a uma compreensão mais coerente do contexto a nossa volta, ou seja: a felicidade requer uma forma lúcida de viver. Isso incluiria uma série de processos humanos, reguladores, assim como os aspectos materiais, sexuais, intelectuais, emocionais e espirituais da vida. Para esse autor tais dimensões podem ou não, serem adaptativos, dependendo do grau de consciência das pessoas, da consciência dos seus valores e de seus objetivos. Do grau de coerência dos seus pensamentos e relacionamentos humanos, poderia inferir-se o quão seriam capazes de conduzir-se a um estado de harmonia e de felicidade.

Em geral, as pessoas entendem a felicidade verdadeira, como um emaranhado de intensos sentimentos positivos, que acarreta sensação de plenitude e de paz. Isso independeria de como seja definida. A felicidade tem um componente emocional, talvez por isso, seja percebida diferentemente pelas pessoas, com algum ponto de regulação, possivelmente, definido geneticamente na personalidade de cada um.

A sensação de felicidade de cada ser humano, pressupõe reflexões cognitivas e, análises socias ante as crenças individuais. Somente parte desta sensação parece ter a ver com o que a pessoa sente. $\mathrm{O}$ restante seria produto de uma produção mental calculada, em que se computam expectativas, referenciando-se em modelos ideais, dentre outros inúmeros fatores. Portanto, a felicidade é um estado mental, que nos parece estratégico e intencional.

São inúmeras as receitas orientadas por livros de autoajuda disponíveis, embora a felicidade possa vir de onde menos se espera. Seguem-se algumas possibilidades, mais corriqueiramente citadas na literatura:

1 - Correr riscos, desafiar-se a sair da zona de conforto, pode trazer a sensação de aventura, de crescimento pessoal, já que ao vivenciar algo novo, agregamos experiência de vida e conhecimentos novos, o que traria uma sensação de conforto e felicidade (STEGER et al., 2009);

2 - Prestar atenção aos detalhes é uma questão de sobrevivência emocional. Pessoas felizes são mais a vontade com os outros, mais benevolentes. Vivem sem se concentrar nos 
perigos e armadilhas sociais do mundo que nos rodeia (FORGAS, 2001).. Pessoas satisfeitas são menos atentas aos detalhes, o que as fazem presas fáceis a mentiras e golpes.

3 - Congratular-se com o sucesso das pessoas e dos amigos. Esta é uma fórmula que nos ajuda a sentir uma pessoa melhor (ELLIOT, MCGREGOR e GABLE, 1999). As pessoas são mais felizes quando estão presentes nos momentos de sucesso dos amigos e pessoas queridas.

4 - Conseguir reconhecer seus sentimentos, mesmo aqueles que são negativos ou pessimistas. Desenvolver à partir disso uma habilidade de modificar seu estado mental, ajudaria a manter um estado emocional mais voltado para o bem estar (BONANNO, 2004). Tal habilidade envolveria prestar atenção ao que se fala e a maneira de posicionar o corpo.

5 - Adiar um prazer imediato, em detrimento de alcançar-se metas mais apropriadas e duradouras no futuro, pode proporcionar maior felicidade (STEGER, 2009). Furtar-se de um doce, sair da cama mais cedo para cumprir um programa de caminhada, pode a longo prazo proporcionar maior felicidade, do que manter-se preso aos pequenos prazeres que podem não estarem alinhados com sua meta principal.

Talvez sejam essas, apenas algumas das possibilidades de tornar nossas vidas um pouco mais prazerosas e felizes.

Pode-se concluir que a felicidade, além de ser um fenômeno eminentemente subjetivo, estaria subordinada a certos traços de personalidade, temperamento e a postura diante da vida, do que mesmo a fatores determinados e previsíveis. Isto nos leva a crer, serem questões do campo de estudo da Psicologia e da Psiquiatria, áreas da ciência que tem ampliado suas formas de perceber e lidar com esse fenômeno, muito mais do que, somente propor atitudes ou "fórmulas" para alívio dos sintomas mentais. Mesmo assim, ainda são iniciativas incipientes, principalmente quanto a orientar estratégias eficazes de promoção da saúde mental, com características específicas para a população brasileira.

\section{Referências}

BONANNO, G. A. Loss, trauma and human resilience. American Psychologist, 59(1), 20-28, 2004. 
CLONINGER, C.R. - Feeling good: the science of well-being. Oxford University Press, New York, 2004.

CLONINGER, C.R. - The science of well-being: an integrated approach to mental health and its disorders. World Psychiatry 5: 71-76, 2006.

CSIKSZENTMIHALYI, M. Flow: The psychology of optimal experience. New York: Harper \& Row, 1990.

DICIONÁRIO ON LINE DE PORTUGUÊS. Disponível em: <_https://www.dicio.com.br/>. Acesso em 12.07.2018.

DIENER, E. Subjective well-being. Psychological Bulletin, 95(3), 542-575, 1984.

ELLIOT, J. A., MCGREGOR, H. A., e GABLE, S. Achievement goals, study trategies, and exam performance: A mediational analysis. Journal of Educational Psychology, 1999, 91 (3), 549-563.

EKMAN, P. - Are there basic emotions? Psychol Ver, 1992, 99: 550-553.

FORGAS, Joseph. P. Affective intelligence: The role of affect in social thinking and behaviour. Em: J. Ciarrochi, J. P. Forgas, \& J. D. Mayer (Eds.) Emotional intelligence and everyday life (pp.46-63). New York: Psychology Press, 2001.

SELIGMAN, M.E.P.; CSIKSZENTMIHALYI, M. - Positive psychology: an introduction. Am Psychol 55(1): 5-14, 2000.

STEGER, M. F., MANN, J. R., MICHELS, P., \& COOPER, T. C. Meaning in life. In S. J. Lopez (Ed.), Handbook of positive psychology ( $2^{\text {nd }}$ ed., pp. 679-689). Oxford, UK: Oxford University Press, 2009.

STEGER, M. F. Meaning in life. In S. J. Lopez (Ed.), Oxford handbook of positive psychology (2nd ed., pp. 679-687). Oxford: Oxford University Press, 2009.

PETERSON, C. e SELIGMAN, M. Character strengths and virtues: A handbook and classification. Washington, DC: American Psychological Association, 2004.

\section{Como citar este artigo (Formato ABNT):}

OLIVEIRA, Gislene Farias de. A Ciência explica a Felicidade?. Id on Line Rev.Mult. Psic., 2018, vol.12, n.41, p.1027-1032. ISSN: 1981-1179.

Recebido: 11/07/2018.

Aceito: $26 / 07 / 2018$ 